\title{
Virtual-Flux Direct Power Control for Mains Connected Three-Level NPC Inverter Systems
}

\author{
Leonardo A. Serpa Non-member (Swiss Federal Institute of Technology) \\ Johann W. Kolar Member (Swiss Federal Institute of Technology)
}

Keywords: direct power control, grid connected, three-level NPC

For high power systems the use of direct power control (DPC) is spreading in the last few years due to the advantages, such as a fast dynamics and simplicity, when compared with other methods. For instance the voltage oriented control method guarantees a high static performance via an internal current control loop but suffers from a low dynamic performance and is affected by the stability requirements of the feedback loop. Predictive control gives optimal performances, in terms of both response time and accuracy; however it involves considerable calculation effort and requires a good knowledge of load parameters.

The basic idea of the DPC approach is the direct control of active and reactive power without any internal control loop or PWM modulator. The switching states are selected via a switching table and the states are chosen based on the instantaneous error between the estimation and the desired active and reactive power.

Traditionally, the DPC was investigated for low power applications where normally the standard two-level topology is employed. However, high voltage applied to the semiconductors limits the use of this topology for high power and high voltage applications, an area in which multilevel inverters are emerging.

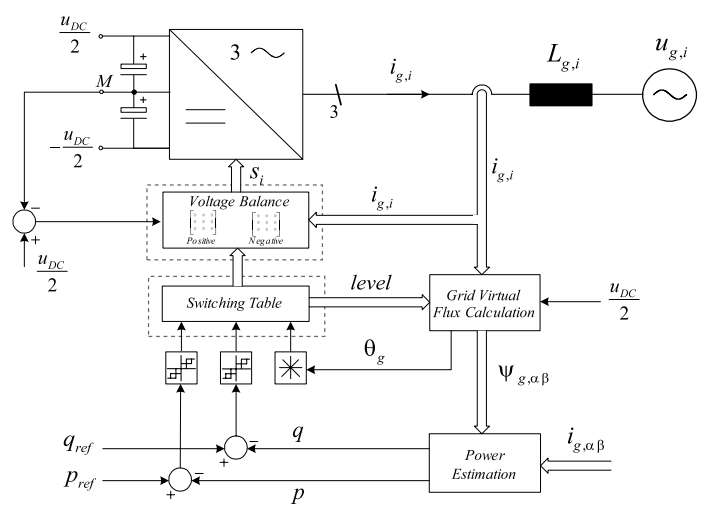

Fig. 1. Block scheme of the VF-Direct Power Control for three-level NPC inverter
Since its introduction in 1981, the three-level neutral-pointclamped(NPC) voltage source inverter has demonstrated some advantages over the conventional two-level inverter. It has been applied in medium and high power applications due to the inherent advantages, namely: voltage across the switches is clamped to half of the dc-link, produces low output voltage and current harmonic distortion and reduces the $\mathrm{dv} / \mathrm{dt}$ stress on the load. However, the NPC-VSI has a problem that excessive high voltages may be applied to switching devices, when the floating neutral point potential varies from the mid-potential of the dc-link voltage.

Therefore, to take full advantage of this topology the mid-point of the dc-link must remain clamped at one half of the complete dclink voltage. The possibility of influencing the mid-point potential is based on the existence of redundant switch states concerning the voltage space vector generated at the output of the inverter. The redundant switching states are characterized by opposite loading of the mid-point current. Therefore, this allows the control of the midpoint potential without any influence on the output voltage.

When using a three-level inverter, the selection of the output voltage vectors becomes more complex due to higher number of available states, however it provides more flexibility to choose an appropriate voltage vector.

For high power applications a third order output filter that can achieve reduced levels of harmonic distortion at lower switching frequencies and with less total inductance is usually employed. However, systems incorporating LCL filters require extra control effort in order to compensate undesirable characteristics such as the filter resonance.

This paper proposes a control strategy which extends the VirtualFlux Direct Power Control traditionally employed for the conventional two-level VSI to a three-level NPC inverter. This topology generates a higher number of output voltage levels, increasing the flexibility for selecting an appropriate voltage vector. The mid-point potential is controlled according to the direction of the mid-point current and the sign of the mid-point voltage deviation. The method is adapted to be used with an LCL output filter, where some undesirable characteristics, such as filter resonance, have to be compensated. 


\title{
Virtual-Flux Direct Power Control for Mains Connected Three-Level NPC Inverter Systems
}

\author{
Leonardo A. Serpa* Non-member \\ Johann W. Kolar* Member
}

\begin{abstract}
This paper proposes a control strategy which extends the Virtual-Flux Direct Power Control traditionally employed for the conventional two-level VSI to a three-level NPC inverter. This topology generates a higher number of output voltage levels, increasing the flexibility for selecting an appropriate voltage vector. The mid-point potential is controlled according to the direction of the mid-point current and the sign of the mid-point voltage deviation. The method is adapted to be used with an LCL output filter, where some undesirable characteristics, such as filter resonance, have to be compensated. Further investigation concerning the dependency of the mid-point voltage with the current phase-shift is given. Theoretical analysis is presented and the performance of the proposed method is verified by simulation.
\end{abstract}

Keywords: direct power control, grid connected, three-level NPC

\section{Introduction}

For high power systems the use of direct power control (DPC) is spreading in the last few years due to the advantages, such as a fast dynamics and simplicity, when compared with other methods. For instance the voltage oriented control method ${ }^{(1)}$ guarantees a high static performance via an internal current control loop but suffers from a low dynamic performance and is affected by the stability requirements of the feedback loop. Predictive control ${ }^{(2)}$ gives optimal performances, in terms of both response time and accuracy; however it involves considerable calculation effort and requires a good knowledge of load parameters.

The basic idea of the DPC approach is the direct control of active and reactive power without any internal control loop or PWM modulator. The switching states are selected via a switching table and the states are chosen based on the instantaneous error between the estimation and the desired active and reactive power.

Traditionally, the DPC was investigated for low power applications ${ }^{(3)}$ where normally the standard two-level topology is employed. However, high voltage applied to the semiconductors limits the use of this topology for high power and high voltage applications, an area in which multilevel inverters are emerging.

Interest on the high power area has increased also on the field of motor control. The Direct Torque Control, equivalent to DPC in machine applications, has been extended to be used with the classic three-level NPC inverter ${ }^{(4)(5)}$. Tan et al. ${ }^{(4)}$ have proposed a slightly different approach, where a combination of vectors, called virtual vector, are applied in one sample

Based on "Virtual-Flux Direct Power Control for Mains Connected Three-Level NPC Inverter Systems" by L.A. Serpa and J.W. Kolar which appeared in the proceedings of the 2007 Power Conversion Conference-Nagoya, (c)2007 IEEE.

* Swiss Federal Institute of Technology-ETHZ

Physikstrasse 3, CH-8092 Zurich period rather then just one vector of the conventional DTC. This strategy is used to proper balance the dc-link mid-point voltage and avoids high $\frac{d v}{d t}$ between two successive vectors. The same problem is analyzed in Ref. (5), where constraints are included, limiting the switch transitions between output vectors. An extension of the DPC technique for three-level converters has been also proposed ${ }^{(6)}$, however it substitutes the switching table decision by the conventional space vector modulation. As consequence, the fast dynamic performance inherent to the conventional DPC approach is lost.

Since its introduction in $1981^{(7)}$, the three-level neutralpoint-clamped (NPC) voltage source inverter (Fig. 1) has demonstrated some advantages over the conventional twolevel inverter. It has been applied in medium and high power applications due to the inherent advantages, namely: voltage across the switches is clamped to half of the dc-link, produces low output voltage and current harmonic distortion and reduces the $\mathrm{dv} / \mathrm{dt}$ stress on the load. However, the NPC-VSI has a problem that excessive high voltages may be applied to switching devices, when the floating neutral point potential varies from the mid-potential of the dc-link voltage.

Therefore, to take full advantage of this topology the midpoint of the dc-link must remain clamped at one half of the complete dc-link voltage. The possibility of influencing the

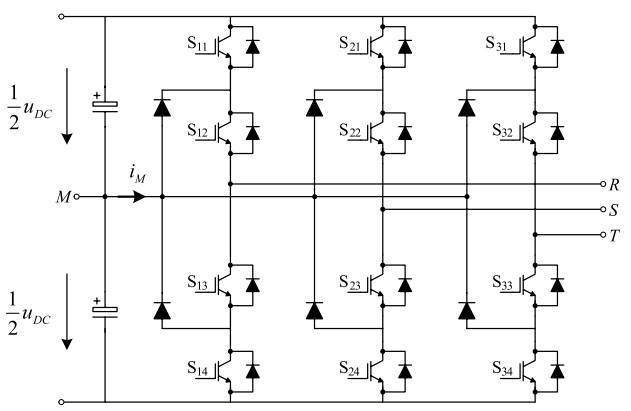

Fig. 1. Three-Phase Three-Level NPC VSI 
mid-point potential is based on the existence of redundant switch states concerning the voltage space vector generated at the output of the inverter ${ }^{(8)}$. The redundant switching states are characterized by opposite loading of the mid-point current $^{(9)}$. Therefore, this allows the control of the mid-point potential without any influence on the output voltage.

When using a three-level inverter, the selection of the output voltage vectors becomes more complex due to higher number of available inverter states, however it provides more flexibility for choosing an appropriate voltage vector.

For high power applications a third order output filter that can achieve reduced levels of harmonic distortion at lower switching frequencies and with less total inductance is usually employed. However, systems incorporating LCL filters require extra control effort in order to compensate undesirable characteristics such as the filter resonance.

This paper presents a sensorless direct power control scheme, employing a three-level NPC inverter connected to the grid. The proposed scheme includes a special method to avoid a dc-link capacitor voltage unbalance. In Section 2 the basic concept of direct power control is discussed and the calculation of active and reactive power estimation is given. In order to adapt the standard DPC to be used with three-level inverter, a strategy to increase the number of utilized space vectors as well as a method for balancing the mid-point potential is presented in Section 3. The basis of controlling the potential of the mid-point $M$ is given by the knowledge of the mid-point current $i_{M}$ and the mid-point voltage deviation. The proposed approach is proved by simulation in Section 4. Section 5 adapts the virtual-flux direct power control (VF-DPC) for a system with third order LCL filter. An active damping and harmonic control based on power quantities are included to the system. Finally, Section 6 verifies the extended method by simulation, where the system is tested with distorted grid voltage and with pure reactive power load.

\section{Principle of Direct Power Control}

The basic principle of the Direct Power Control (DPC) was proposed by Noguchi ${ }^{(3)}$ and is based on the well know Direct Torque Control (DTC) for induction machines. In the DPC, the active and reactive powers replace the torque and flux amplitude used as the controlled output in the DTC. The basic concept consists of selecting the appropriate switching states from a switching table based on the errors, which are limited by a hysteresis band, present in the active and reactive powers as illustrated in Fig. 2.

In order to correctly estimate the power and at the same time reduce the numbers of implemented voltage sensors, Noguchi proposes the use of voltage vector estimation. The implementation of such approach involves the computation of the time derivative of the measured currents. The use of a derivative can increase the noise in the control loop, thus increasing the level of distortion.

Recently the Virtual Flux strategy was proposed ${ }^{(10)}$, which assumes basically that the grid voltage and the ac-side inductors are quantities that are related to a virtual ac motor. Making an analogy with ac motors, $R_{g}$ and $L_{g}$ (Fig. 3) represent the stator resistance and the stator leakage inductance respectively and the grid voltage, represents the machine's electro-motive force.

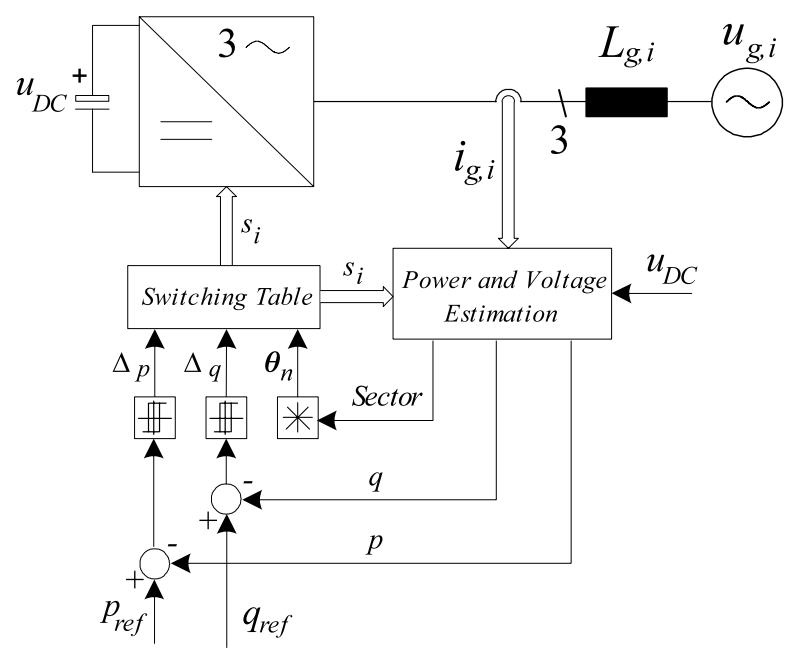

Fig. 2. Block diagram of conventional Direct Power Control

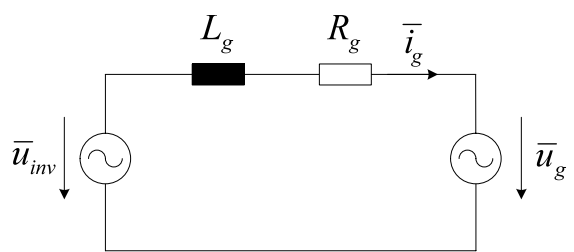

Fig. 3. Equivalent circuit of a grid connected threephase VSI with L filter

Applying the flux definitions of Eq. (1) and the voltage loop equation of Eq. (2), the grid virtual flux can be estimated.

$$
\begin{aligned}
& \bar{\psi}_{g}=\int \bar{u}_{g} \cdot d t \ldots \ldots \ldots \ldots \ldots \ldots \ldots \ldots \ldots \ldots \ldots \ldots \ldots \ldots \ldots \ldots \ldots
\end{aligned}
$$

Neglecting the series resistance of the line inductor, the line virtual flux can be calculated based on the measured line current $\bar{i}_{g}$ and the inverter voltage $\bar{u}_{i n v}$

$$
\bar{\psi}_{g}=\int \bar{u}_{i n v} \cdot d t-L_{g} \cdot \bar{i}_{g} \ldots \ldots \ldots \ldots \ldots \ldots \ldots \ldots
$$

where the inverter output voltage in the stationary coordinate system can be calculated based on the dc-link voltage and the converter switching states.

Based on the grid virtual flux and current the active and the reactive power, as developed in Ref. (10), can be estimated as

$$
\begin{aligned}
& p=\frac{3}{2} w \cdot\left(\psi_{g, \alpha} \cdot i_{g, \beta}-\psi_{g, \beta} \cdot i_{g, \alpha}\right) \\
& q=\frac{3}{2} w \cdot\left(\psi_{g, \alpha} \cdot i_{g, \alpha}+\psi_{g, \beta} \cdot i_{g, \beta}\right)
\end{aligned}
$$

where the stationary $(\alpha \beta)$ transformation is according to

$$
\left[\begin{array}{l}
u_{\alpha} \\
u_{\beta}
\end{array}\right]=\frac{2}{3}\left[\begin{array}{ccc}
1 & \frac{-1}{2} & \frac{-1}{2} \\
0 & \frac{\sqrt{3}}{2} & \frac{-\sqrt{3}}{2}
\end{array}\right]\left[\begin{array}{l}
u_{R} \\
u_{S} \\
u_{T}
\end{array}\right] \ldots
$$

\section{VF-DPC for Three-Level NPC Inverter}

In the Neutral-Point Clamped inverter presented in Fig. 1, 


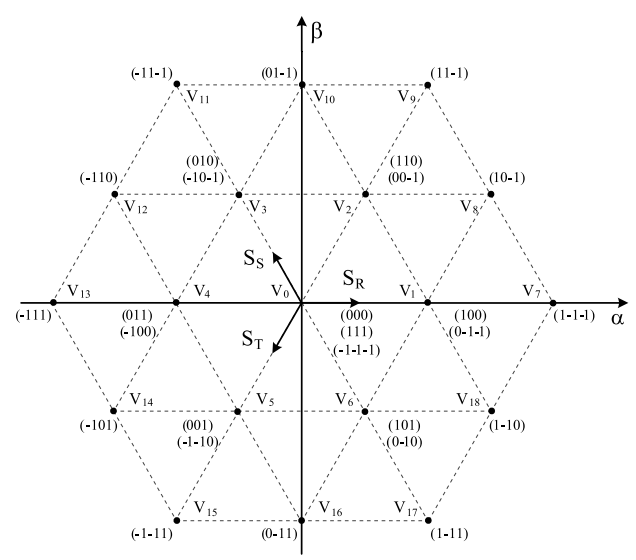

Fig. 4. Space vector diagram of three-level inverter

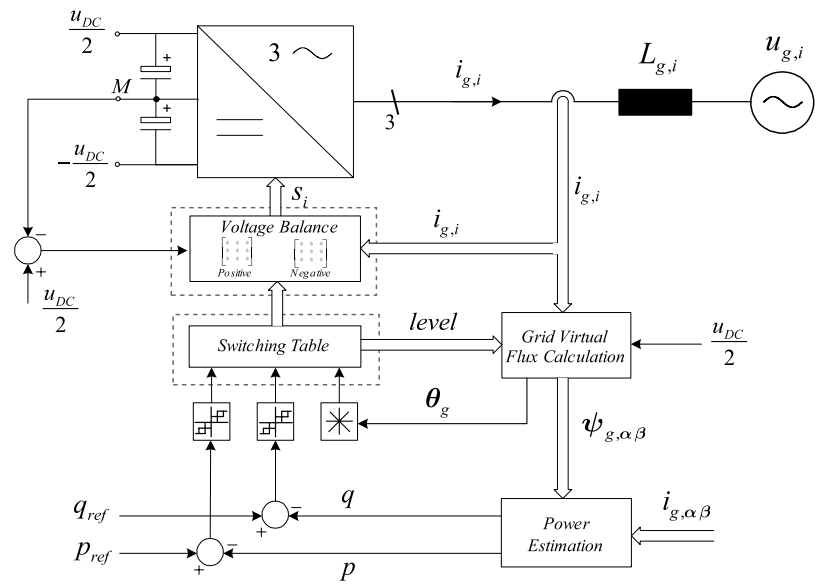

Fig. 5. Block scheme of the VF-Direct Power Control for three-level NPC inverter

each phase can produce three distinct levels by connecting the output either to the positive $\left(\frac{u_{D C}}{2}\right)$, negative $\left(\frac{-u_{D C}}{2}\right)$ or null (0) potential. In a three-phase system it results in $3^{3}=27$ output voltage vectors. The output voltage space vector can be classified into four categories according to its magnitude, namely: zero space vector $V_{0}$ which corresponds to three configurations that produces null output voltage, half vectors $\left(V_{1}, V_{2}, V_{3}, V_{4}, V_{5}\right.$ and $\left.V_{6}\right)$ that create a voltage space vector with amplitude equal to $\frac{u_{D C}}{3}$, medium vectors $\left(V_{8}, V_{10}, V_{12}\right.$, $V_{14}, V_{16}$ and $\left.V_{18}\right)$ with an amplitude of $\sqrt{3} \cdot \frac{u_{D C}}{3}$ and the full voltage vectors $\left(V_{7}, V_{9}, V_{11}, V_{13}, V_{15}\right.$ and $\left.V_{17}\right)$ that generate a space vector with amplitude equal to $2 \cdot \frac{u_{D C}}{3}$.

Although in a three-level inverter there are 27 possible states, some of them apply the same voltage vector. There are two possible configurations for each small vector and three for the zero vectors. Therefore, 19 different vectors $V_{0}$ to $V_{18}$ are available as shown in Fig. 4.

The voltage vectors are identified for example by $\left(\begin{array}{lll}1 & 0\end{array}\right)$ or (1 $0-1)$, where each column represents one phase (R, S and $\mathrm{T})$ and the numbers 1, 0 and -1 indicate the phase connection to the positive, neutral and negative point of the dc-link, respectively.

The proposed VF-DPC scheme (Fig. 5) to be employed with three-level NPC inverter is a natural extension of the classical VF-DPC ${ }^{(10)(11)}$ used previously for two-level systems. Some modification must be done in order to minimize

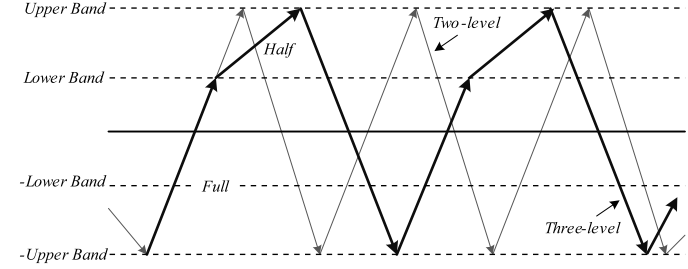

Fig. 6. Active or reactive power error variation in two and three-level inverters

the output voltage harmonic distortion and to assure the balance of the mid-point voltage by appropriate selection of the redundant vectors.

Fig. 5 shows that the main idea of the VF-DPC is maintained. The inverter switching states are appropriately selected by a switching table according to the instantaneous error between references and estimated values of active and reactive power. However, to permit more flexibility in the vector selection, a single band hysteresis is replaced by a double band strategy and to achieve a proper mid-point balancing, a method to decide on the correct redundant vector is employed.

3.1 Voltage Vector Selection With 27 possible choices for space vector selection, the Switching Table in three-level inverters becomes more complex comparing with two-level inverters, however it allows much more possibilities for appropriate voltage vector selection to satisfy the commutation condition.

In order to utilize this benefit, a double band hysteresis method is applied as shown in Fig. 6.

When active/reactive power error comes down to negative upper band, a full voltage vector is chosen. A half vector replaces the full vector when the error reaches the positive lower band, resulting in a lower slope of the active or reactive power. If the error increases beyond the positive upper band, a full voltage vector is applied to decrease the error or increase the instantaneous active or reactive power.

As consequence of selecting more voltage space vectors in the three-level inverter DPC, the harmonic content in the output voltage and current can be reduced.

3.2 Mid-Point Balance The mid-point balance is not influenced by all the vectors. Large vectors do no affect the mid-point balance, since the phase currents are connected to either the positive or negative potential. Medium vectors connect one of the phase currents to the mid-point making the $M$ potential dependent on the load conditions. They are the most important source of mid-point potential unbalance. As mentioned before, small vectors come in pair, as shown, for example, by the vector $V_{1}$ in Fig. 7. These states apply equivalent voltages to the output; however the orientation of the mid-point current differs. In one state, the current flows out of $M$, effectively discharging the lower capacitor of the dclink while charging the upper capacitor. In the opposite state, the current flows into the mid-point, charging the lower capacitor and consequently discharging the upper capacitor.

An illustration of the effect caused by redundant switching states $\left(\begin{array}{lll}0 & -1 & -1\end{array}\right)$ and $\left(\begin{array}{lll}1 & 0 & 0\end{array}\right)$ of the space vector $V_{1}$ in the mid-point current can be seen in Fig. 8. Although the lineto-line voltages produced by both switching states are identical $\left(u_{R S}=\frac{u_{D C}}{2}, u_{S T}=0\right.$ and $\left.u_{T R}=\frac{-u_{D C}}{2}\right)$, the mid-current 


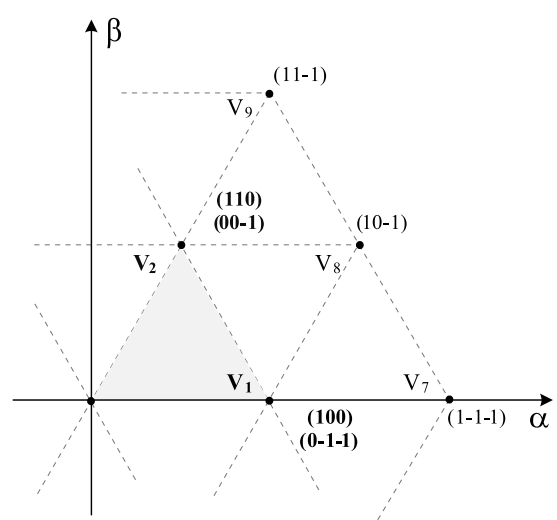

Fig. 7. Redundant vectors presented in the voltage space vectors of a three-level inverter

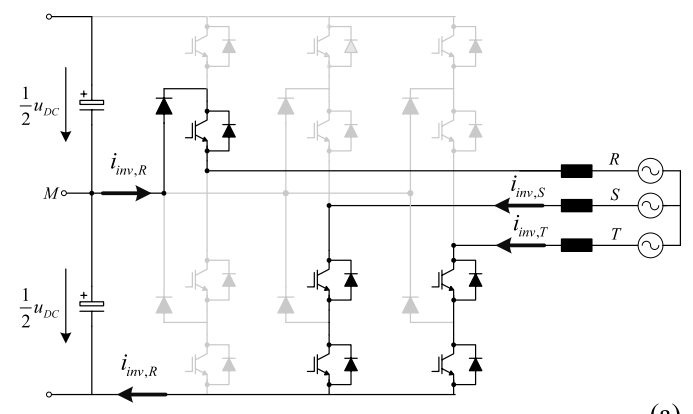

(a)

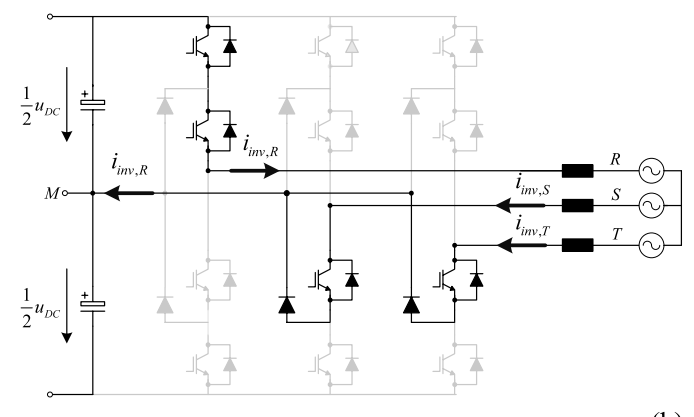

(b)

Fig. 8. Influence caused by the redundant vector in the mid-point current (a) positive small vector $(0-1-1)$ and (b) negative small vector $\left(\begin{array}{lll}1 & 0 & 0\end{array}\right)$

generated are in opposite direction.

Assuming positive current in the phase $\mathrm{R}$ and negative current in the phases $\mathrm{S}$ and $\mathrm{T}$, the mid-point current flows out of the mid-point when the state $(0-1-1)$ is selected (Fig. 8(a)). In this case the upper capacitor is charged and the lower capacitor is discharged. An opposite effect on the capacitors voltages is observed when the state $\left(\begin{array}{lll}1 & 0 & 0\end{array}\right)$ is choose, since the mid-point current now flows into the mid-point, as shown in Fig. 8(b).

The presence of these redundant vectors creates a degree of freedom for controlling the mid-point potential by knowing $i_{M}$ and the mid-point voltage deviation.

The deviation is measured by the difference between the voltage reference and the voltage across the lower capacitor, as shown in Eq. (7).

$$
\Delta u_{C_{l}}=u_{C_{l, \text { ref }}}-u_{C_{l}}
$$

Each phase has influence on the mid-point current $i_{M}$ only when the respective phase is connected to the mid-point

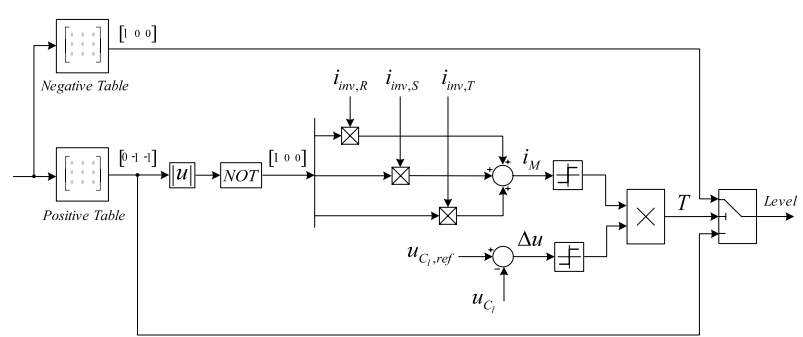

Fig. 9. Block diagram of the Mid-Point voltage control

Table 1. Logic decision among positive and negative table

\begin{tabular}{rr|r}
$i_{M}$ & $\Delta u_{C_{l}}$ & \multicolumn{1}{c}{$T$} \\
\hline-1 & -1 & 1 \\
-1 & 1 & -1 \\
1 & -1 & -1 \\
1 & 1 & 1
\end{tabular}

potential. Therefore, $i_{M}$ can be calculated based on the measured phase currents and the state of each phase:

$$
i_{M}=m p_{R} \cdot i_{i n v, R}+m p_{S} \cdot i_{i n v, S}+m p_{T} \cdot i_{i n v, T}
$$

where $m p_{i}$ is equal to 1 if the phase $i=R, S, T$ is connected to the mid-point potential, and 0 when the phase is connected either to the positive or negative potential.

Based on the direction of the generated $i_{M}$ and the lower capacitor voltage deviation $\left(\Delta u_{C_{l}}\right)$, the controller selects the appropriate redundant state, as shown in Fig. 9.

The switching table is divided into a positive and a negative part, which contain the same structure except the small vectors (redundant) that are allocated according to the effect on the mid-point current. A small vector that produces a positive $i_{M}$ will be referred as a positive small vector and the one which generates a negative $i_{M}$, will be called as a negative small vector.

Initially, the vector to be applied to the NPC inverter is selected by the positive switching table, according to the hysteresis and sector indication. By knowing the state to be applied and the instantaneous measured phase currents, the resulting $i_{M}$ is predicted using Eq. (8). If the predicted $i_{M}$ would increases even more the mid-point potential deviation, the opposite redundant vector is selected by switching to the negative switching table.

For example, the hysteresis and sector indicate the small vector $V_{1}$ as the appropriate choice. A priori the positive small state $(0-1-1)$ is selected by the positive switching table. As a result, according to Eq. (8), the mid-point current is identical to the current in phase $R$, since only this phase is directly connected to the mid-point $M$.

Assuming a positive current in phase $R$ and a positive capacitor voltage deviation $\left(u_{C_{l}}>0\right)$, if the chosen state $(0$ $-1-1)$ is applied to the NPC inverter, a resulting positive $i_{M}=i_{i n v, R}$ would discharge the lower capacitor, consequently increasing the deviation. In this case the opposite negative small vector $\left(\begin{array}{lll}1 & 0 & 0\end{array}\right)$, which generates a negative current, $i_{M}=-i_{i n v, R}$, must be employed to charge the lower capacitor and reduce the voltage deviation.

The logic decision to switch among the positive and negative table is summarized in Table 1 . If both $i_{M}$ and $u_{C_{l}}$ have the same signal, either positive (1) or negative $(-1)$, the 

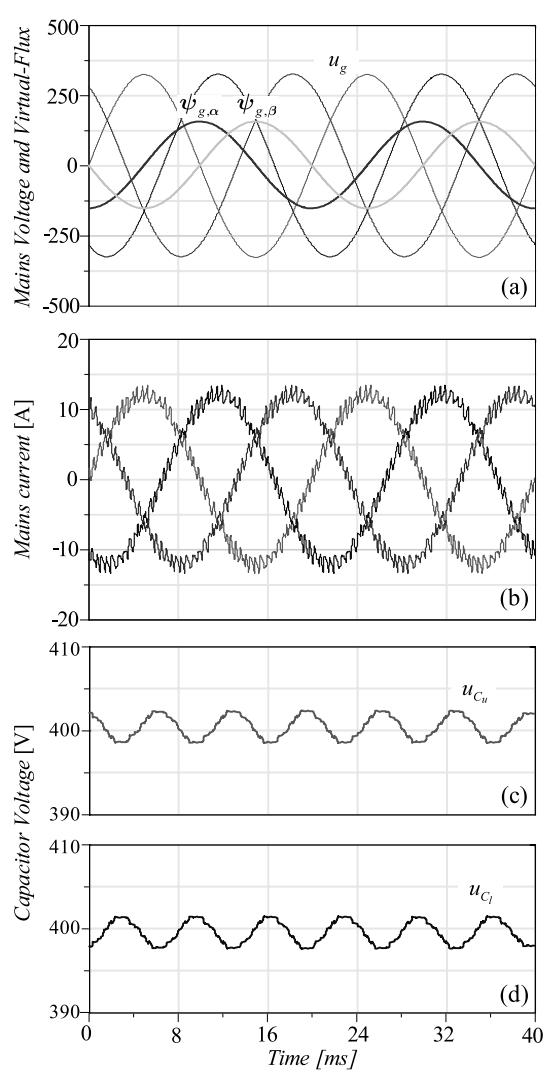

Fig. 10. Simulation results of the proposed VF-DPC with L Filter. Grid voltage and estimated virtual-flux (a), resulting grid current $(\mathrm{b})$ and voltage across the upper and lower dc-link capacitors (upper $u_{C u}$ and lower $u_{C l}$ ) (c)(d)

negative switching table is selected $(\mathrm{T}=1)$, otherwise the state choose by the positive table is maintained $(\mathrm{T}=-1)$. This logic can be simply implemented by multiplying $i_{M}$ by $u_{C_{l}}$, as presented in Fig. 9.

\section{Simulation Results}

In order to verify the effectiveness of the proposed VFDPC for three-level NPC inverter, simulations have been performed. The output inductance of $18 \mathrm{mH}$ links between the inverter and the grid (400 V/3-phase). The inverter, designed to operate with an average switching frequency of $2.5 \mathrm{kHz}$, is supplied by an $800 \mathrm{~V}$ DC power source.

The estimated grid virtual-flux $\left(\psi_{g, \alpha \beta}\right)$, lagging in $90^{\circ}$ the grid phase voltage, is showed in Fig. 10(a). The virtual-flux is used to calculate the instantaneous active and reactive power applied to control the grid current illustrated in Fig. 10(b). The grid current is in phase with the grid voltage, since the reactive power reference is set to zero.

Fig. 10(c)(d) show the voltage across the upper and lower dc-link capacitors clamped at one half of the complete dclink voltage. It proves the efficacy of the proposed mid-point voltage control strategy, which uses the benefits of redundant vector.

The low frequency ripple observed on the dc-link capacitors voltage is caused by periodic variation of the mid-point current over the fundamental grid voltage cycle, as shown in the Fig. 11. As described by Ogasawara and Akagi in ${ }^{(12)}$, the fundamental frequency (Fig. 11(b)) of the mid-point current in a three-level inverter is defined as three times the

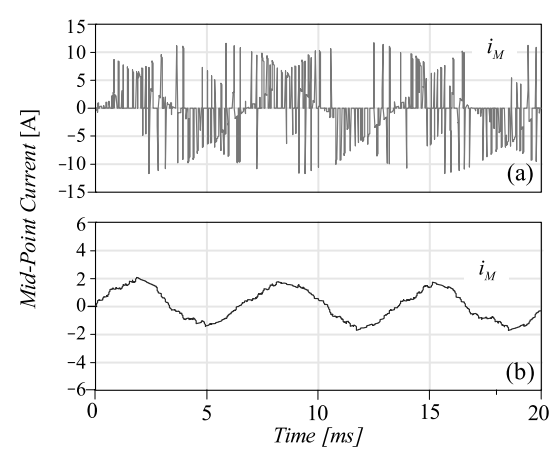

Fig. 11. Simulation results of the mid-point current over one fundamental cycle. (a) Low and high frequency and (b) only fundamental

fundamental grid frequency. Therefore, a grid frequency of $50 \mathrm{~Hz}$ results in a fundamental mid-point current frequency of $150 \mathrm{~Hz}$.

\section{VF-DPC for High Power Application}

The proposed DPC system can be adapted to be used with a third order LCL output filter and therefore achieve reduced levels of harmonic distortion for a VSI operating with a low switching frequency. The LCL filter attenuates the switching ripple substantially and the overall size of the LCL filter is reduced compared to only an L filter. However, systems incorporating LCL filter requires extra control effort in order to compensate some undesirable characteristics such as the filter resonance. The modified VF-DPC showed in Fig. 12 maintains the core of the conventional approach and incorporates outer control loops which damp the filter resonance, reject the influence of grid voltage harmonics ${ }^{(11)(13)}$ and compensate for the reactive power of the capacitor, since the active and reactive power are controlled on the inverter side.

The first aspect to be considered is the grid virtual-flux estimation, which differs from the concept with a series inductor as a filter. In this case the grid side inductor $\left(L_{g}\right)$ flux has to be considered and results in

$$
\bar{\psi}_{g}=\int \bar{u}_{i n v} \cdot d t-L_{i n v} \cdot \bar{i}_{i n v}-L_{g} \cdot\left(\bar{i}_{i n v}-\bar{i}_{c}\right) \cdots \cdots(9)
$$

Since the current ripple on the grid side is significantly reduced by the LCL filter, the hysteresis based DPC must be implemented on the converter side. Therefore, both the active and reactive powers are estimated and controlled on the converter side. The capacitor reactive power is then compensated by adding the estimated capacitor reactive power Eq. (10) to the fundamental reactive power reference $\left(q_{\text {ref }}\right)$.

$$
q_{c}=\frac{3}{2} \omega \cdot\left(\psi_{c, \alpha} \cdot i_{c, \alpha}+\psi_{c, \beta} \cdot i_{c, \beta}\right)
$$

Traditionally, the active damping is designed to act directly on the modulation index or through a common control signal as proposed in Ref. (14), where the damping is performed by feeding the capacitor current feedback to the control reference. However, in the DPC approach where the switching states are selected via a switching table, there is no modulation index or common control signal within the control loops where outer loops control signal can be directly added. To overcome this limitation the active damping control, as well 


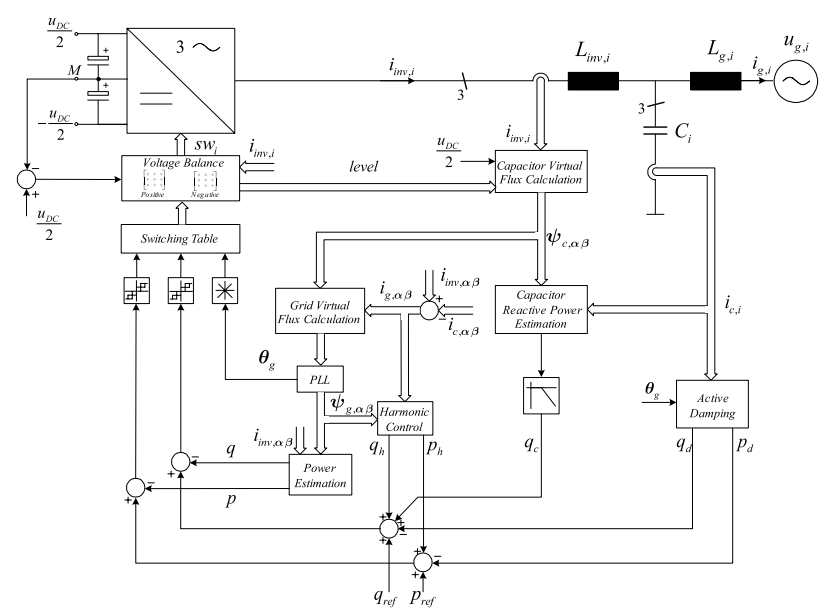

Fig. 12. Block diagram of the extend VF-DPC with active damping, harmonic control, phase-locked loop and reactive power compensation
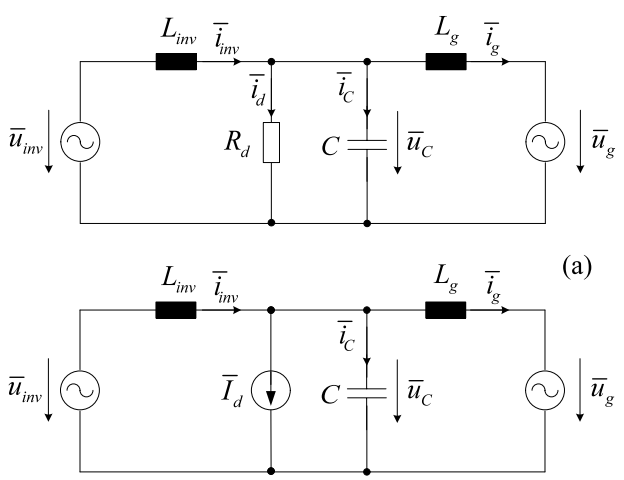

(b)

Fig. 13. Equivalent output stage with (a) passive damping and (b) active damping

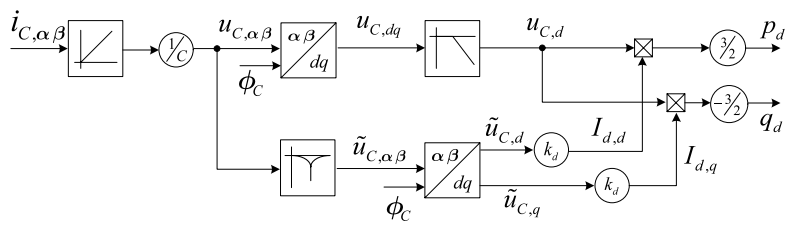

Fig. 14. Active damping block diagram

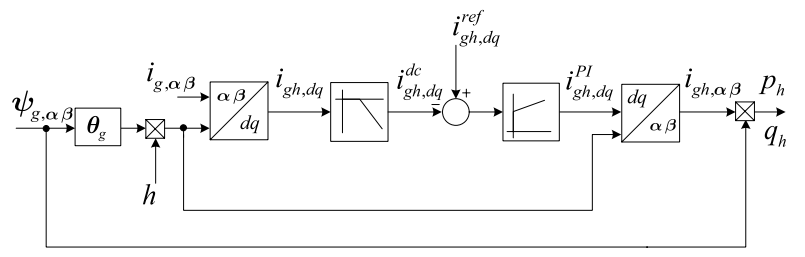

Fig. 15. Harmonic control block diagram

as the individual harmonic rejection control have to be implemented by acting directly on the active and reactive power components. These control signals have to be added to the fundamental references ( $p_{\text {ref }}$ and $q_{\text {ref }}$ ).

The active damping strategy can be applied effectively because the resonance frequency of the output filter is usually inside the bandwidth of the inverter control loops. The active damping is achieved by emulating a resistor in parallel with the filter capacitor by creating a current source proportional to the capacitor voltage resonance component as illustrated
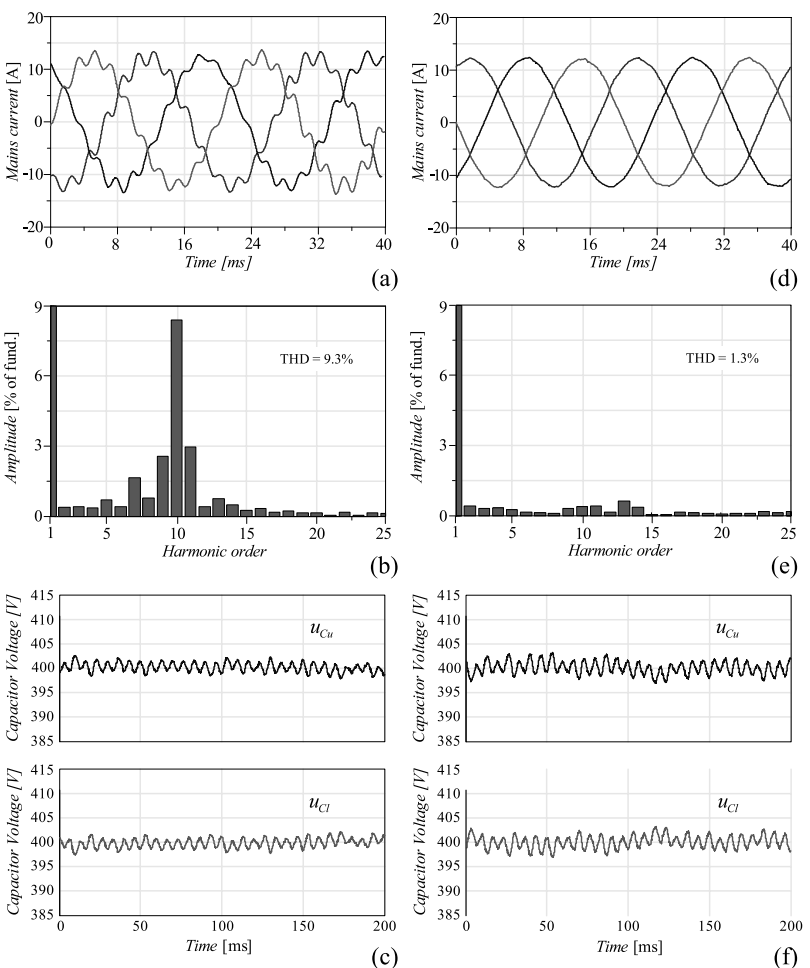

Fig. 16. Simulation results of mains current, respective harmonic spectrum and voltages across the dc-link capacitors (upper $u_{C u}$ and lower $u_{C l}$ ) (a), (b) and (c) provided by conventional DPC and (d), (e) and (f) when the active damping approach and harmonic rejection control loops are added to the main DPC

by the equivalent circuit of Fig. 13.

The active damping scheme is better explained through the block diagram of Fig. 14 . The capacitor voltage $\left(u_{C, \alpha \beta}\right)$ is calculated based on the capacitor current $\left(i_{C, \alpha \beta}\right)$. In order to obtain the proportional damping current source $\left(I_{d, d q}\right)$ value, the resonance component of the capacitor voltage $\left(u_{C, \alpha \beta}\right)$, extracted by eliminating the fundamental frequency component through a notch filter, is transformed to dq coordinates and then is multiplied by the damping factor $\left(k_{d}\right)$. The capacitor voltage needed for calculating power quantities is obtained by converting the stationary reference frame capacitor voltage $\left(u_{C, \alpha \beta}\right)$ to synchronous reference frame components. As the dq transformation is synchronously rotating in the same direction and speed as the capacitor voltage, the fundamental voltage appears as a dc component and the ac parts (harmonics) are suppressed by a low-pass filter.

The capacitor voltage angle $\phi_{C}$ used on the synchronous reference frame transformation can be extracted from the virtual-flux capacitor voltage according to

$$
\phi_{C}=\arctan \left(\frac{\psi_{C, \beta}}{\psi_{C, \alpha}}\right)+\frac{\pi}{2} .
$$

where the angle $\frac{\pi}{2}$ is the difference between voltage and flux quantities.

If the voltage drop on the grid side inductor is assumed to be small in comparison to the grid voltage, the capacitor voltage angle $\phi_{C}$ can be considered equal to the grid virtual-flux angle obtained from the PLL, added to the phase difference between voltage and flux, $\theta_{g}+\frac{\pi}{2}$.

The harmonic control block proposed in Ref. (11)(13) 

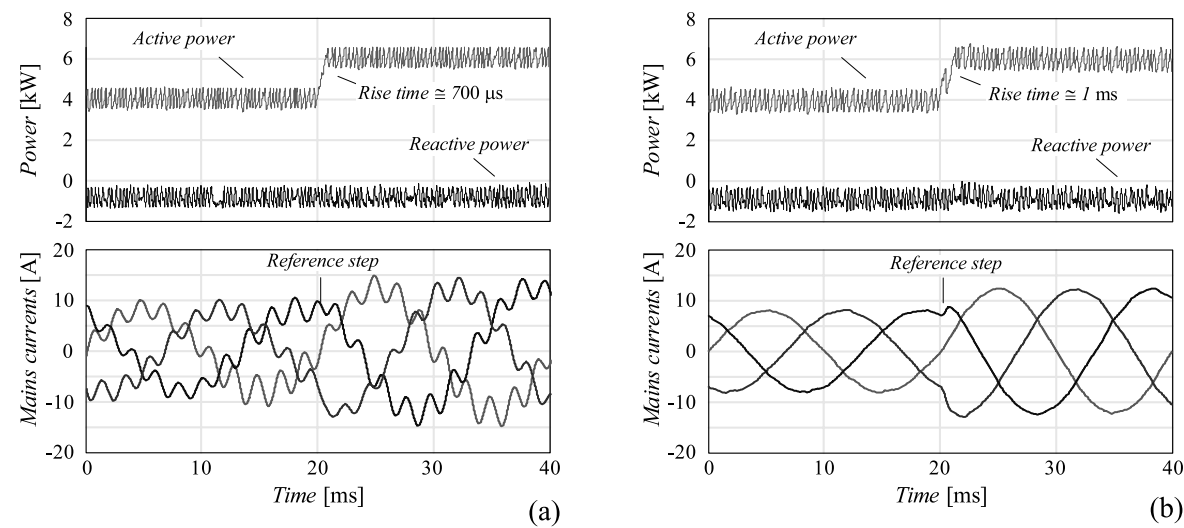

Fig. 17. Simulated time response of the proposed system to a reference step of $35 \%$ on the active power reference
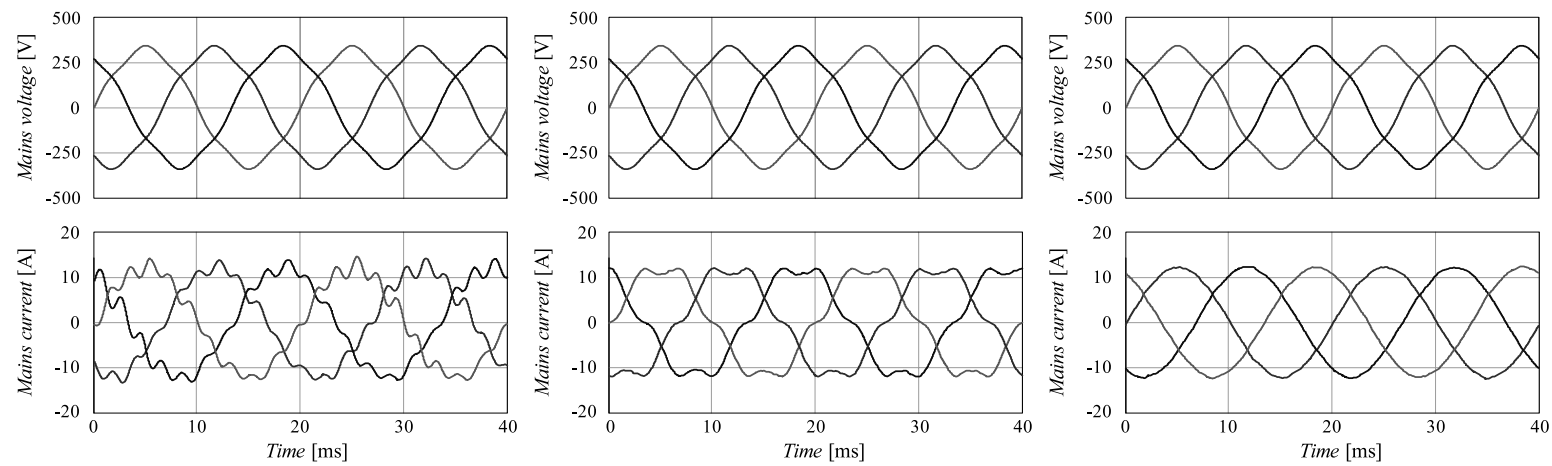

(a)
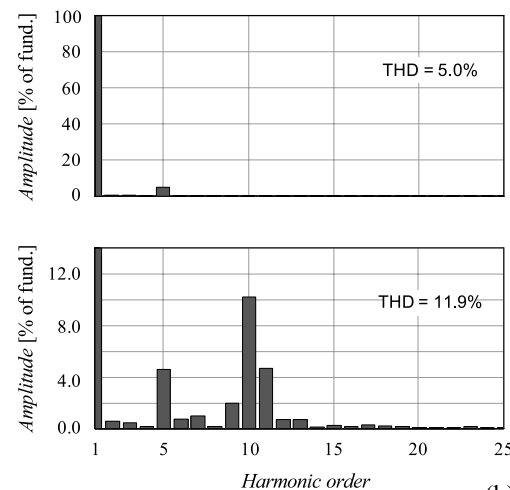

(b)
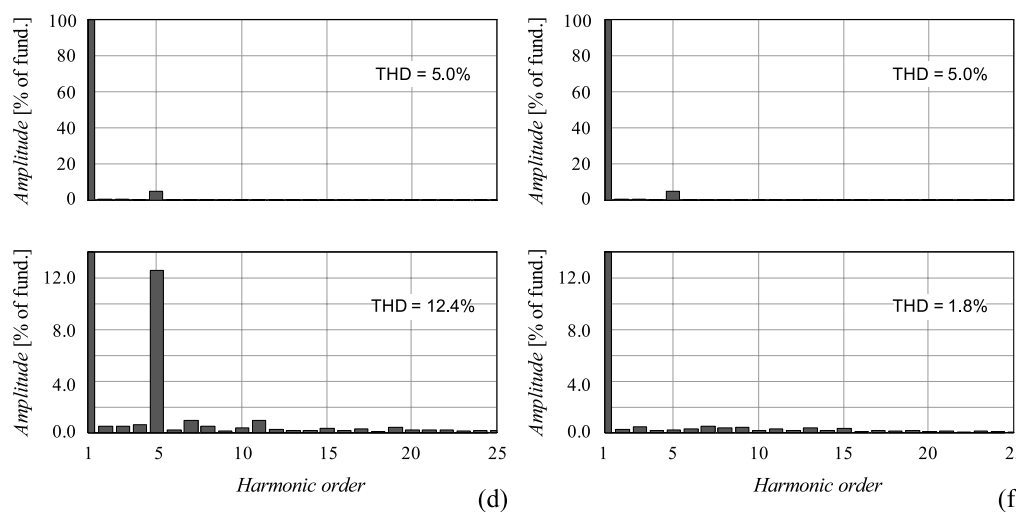

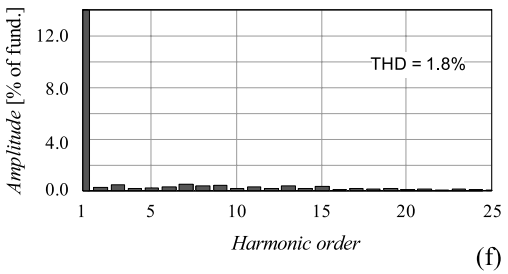

Fig. 18. Simulated results when $5 \%$ of the $5^{\text {th }}$ harmonic is superposed the fundamental grid voltage. Grid phase voltage, current and respective harmonic spectrum for the conventional approach (a), (b), including the active damping (c), (d) and for the proposed scheme with active damping and harmonic control (e), (f)

regulates the harmonics individually in their respective individual synchronous reference frame. Each harmonic quantity to be controlled is transformed into its own individual synchronous reference frame. The corresponding harmonic quantities appear as dc in their own reference frame, consequently a PI control is enough to guarantee zero steady state error.

The block diagram of Fig. 15 shows the basic idea of such approach. The mains side current in the stationary reference frame $\left(i_{g, \alpha \beta}\right)$ is transformed into an individual synchronous reference frame for the harmonic $(h)$ of interest. In order to extract the dc component value (individual desired harmonic) from the output transformation, a first order low-pass filter is used. The dc quantity is then controlled with a PI compensator and transformed back to the stationary reference frame.

Although the practical implementation of these extra control blocks demands digital calculations, for a high sample rate the analyzed continuous models are still valid. Furthermore, assuming the switching frequency of high power applications in the range of few kilohertz, the high sample rate allows neglecting control delays.

\section{Simulation Results for the Extended Approach}

To confirm the efficacy of the extended VF-DPC with an LCL output filter, simulations have been carried out. The setup consists of a $6 \mathrm{~kW}$ NPC inverter, with an averaged switching frequency of around $2.5 \mathrm{kHz}$, connected to a controlled $400 \mathrm{~V}-50 \mathrm{~Hz} 3$-phase AC power source via an LCL filter $\left(L_{i n v}=17 \mathrm{mH}, L_{g}=5.6 \mathrm{mH}\right.$ and $\left.C=18 \mu \mathrm{F}\right)$, designed according to Ref. (15).

The oscillation caused by the filter resonance is reduced when the active damping loop is added to the 

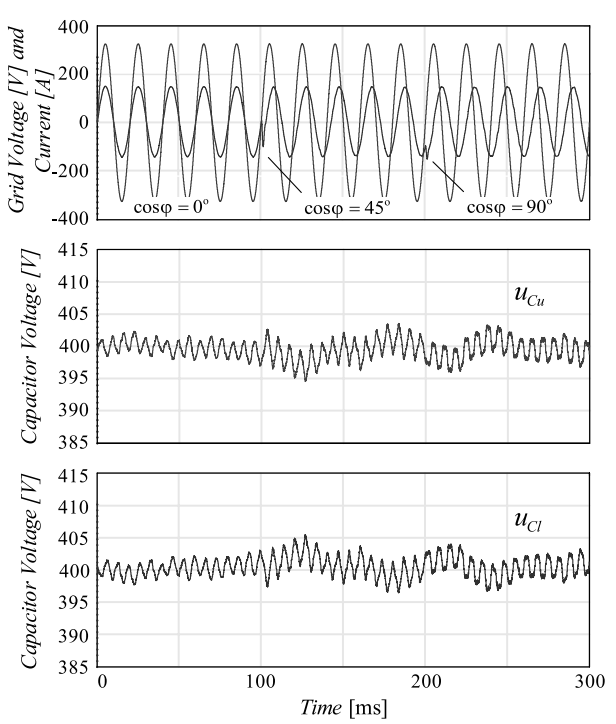

Fig. 19. Dependency analysis of the mid-point voltage with the current phase-shift. The grid current is multiplied by a factor of 10

conventional approach, as can be seen comparing the grid current (Fig. 16(a), (d)) and the respective harmonic spectrum (Fig. 16(b), (e)) for the conventional and extended method. The mid-point balance is guaranteed even when the outer control loops are added to the conventional DPC as shown in Fig. 16 (c), (f).

Although the rise time is increased by $300 \mu \mathrm{s}$, the extended method, Fig. 17(b), reduces significantly the resonance during a step of $35 \%$ on the active power reference.

Fig. 18 shows simulation results in which $5 \%$ of the fifth harmonic component is superposed on the fundamental grid voltage. The effect caused on the grid current by the $5^{\text {th }}$ harmonic is now added to the oscillations due to the filter resonance, resulting in a high total harmonic distortion (THD = $11.9 \%$ ) as shown in the spectrum analysis of Fig. 18(b). By enabling the active damping (Fig. 18(c), (d)) the distortion caused by the resonance is suppressed but on the other hand the effect of the $5^{\text {th }}$ harmonic is amplified, since the capacitor voltage and harmonics present are feedback into the power references. Including the harmonic control, the fifth harmonic influence is also reduced, as can be observed in the grid current presented in Fig. 18(e) and proved by the harmonic spectrum shown in Fig. 18(f). The THD is reduced from $12.4 \%$ to around $1.8 \%$.

The dependency of the mid-point voltage control with the grid current phase-shift is also verified by simulation. Fig. 19 shows the voltage across the dc-link capacitors for three different operation points. Initially, the system is performed with a $\cos \varphi=0$, which assures a proper mid-point balance control. By forcing, at $100 \mathrm{~ms}$, the grid current to lag in $45^{\circ}$ the grid voltage, the oscillations on the capacitors voltage are increased; however the efficacy of the mid-point voltage control remains valid. Similar behaviors on the capacitors voltage are observed at $200 \mathrm{~ms}$ when the phase-shift between voltage and current is increased to $90^{\circ}$.

\section{Conclusion}

An extension of the conventional DPC to be used with a three-level NPC inverter has been presented in this paper. Different hysteresis strategy as well a mid-point potential control are incorporated to the conventional DPC in order to utilize the full advantages of three-level topology. The method is also adapted to be used with a third order LCL filter by adding active damping and harmonic control strategies. Both static and dynamic behaviors were investigated by simulation, as well the efficacy of the mid-point voltage control for different grid voltage and current phase-shift.

(Manuscript received May 9, 2007, revised July 30, 2007)

\section{References}

( 1 ) J. Holtz: "Pulsewidth Modulation-A survey", IEEE Trans. Ind. Electron., Vol.39, No.5, pp.410-420 (1992-10)

( 2 ) R. Wu, S.B. Dewan, and G.R. Slemon: "Analysis of a PWM ac to dc Voltage Source Converter under the Predicted Current Control with a Fixed Switching Frequency", IEEE Trans. Ind. Applicat., Vol.27, No.4, pp.756-763 (19917/8)

( 3 ) T. Noguchi, H. Tomiki, S. Kondo, and I. Takahashi: "Direct Power Control of PWM Converter without Power-Source Voltage Sensors", IEEE Trans. Ind. Applicat., Vol.34, No.3, pp.473-479 (1998-5/6)

( 4 ) Z. Tan, Y. Li, and M. Li: "A Direct Torque Control of Induction Motor Based on Three-level NPC Inverter", in Proc. IEEE PESC'01 Conf., pp.1435-1439 (2001-6)

( 5 ) A. Sapin, P.K. Steimer, and J.J. Simond: "Modeling, Simulation and Test of a Three-level Voltage Source Inverter with Output LC Filter and Diret Torque Control", in Proc. IEEE IAS'03 Conf., pp.492-498 (2003-10)

( 6 ) M. Malinowski, W. Kolomyjski, M.P. Kazmierkowski, and S. Stynski: "Advanced DSP Control of 3-Level DC/AC Converter for Variable-Speed PMSG", in Proc. EPE-PEMC'06, pp.889-894 (2006)

( 7 ) A. Nabae, I. Takahashi, and H. Akagi: "A new neutral-point-clamped PWM inverter”, IEEE Trans. Ind. Applicat., Vol.17, pp.518-523 (1981-9/10)

( 8 ) N. Celanovic and D. Borojevic: "A comprehensive study of neutralpoint voltage balancing problem in three-level neutral-point-clamped voltage source PWM inverters", IEEE Trans. Power Electron., Vol.15, pp.242-249 (2000-3)

( 9 ) K. Yamanaka, A.M. Hava, H. Kirino, Y. Tanaka, N. Koga, and T. Kume: "A Novel Neutral Point Potential Stabilization Technique Using the Information of Output Current Polarities and Voltage Vector", IEEE Trans. Ind. Applicat., Vol.38, No.6, pp.1572-1580 (2002-11/12)

(10) M. Malinowski, M.J. Jasinski, and M.P. Kazmierkowski: "Simple Direct Power Control of Three-Phase PWM Rectifier Using Space-Vector Modulation DPC-SVM)", IEEE Trans. Ind. Electron., Vol.51, No.2, pp.447-454 (2004-4)

(11) L.A. Serpa, S. Ponnaluri, P.M. Barbosa, and J.W. Kolar: "A Modified Direct Power Control Strategy Allowing the Connection of Three-Phase Inverter to the Grid through LCL Filters", in Proc. IEEE IAS'05 Conf., Vol.1, pp.565$571(2005-10)$

(12) S. Ogasawara and H. Akagi: "Analysis of variation of neutral point potential in neutral-point-clamped voltage sources PWM inverters", in Proc. IEEE Ind. Applicat. Soc. (IAS) Conf. Rec., pp.965-970 (1993)

(13) S. Ponnaluri and A. Brickwedde: "Overriding Individual Harmonic Current Control with fast dynamics for Active Filtering", in Proc. IEEE PESC'01 Conf., pp.1596-1601 (2001-6)

(14) T. Tanaka, K. Wada, and H. Akagi: "A Control Scheme for Suppressing Voltage Oscillation on the AC Side of a Series Active Filter", in in Proc. International Conference on Harmonics and Quality of Power 1996, pp.153-158 (1996)

(15) Y. Lang, D. Xu, S.R. Hadianamrei, and H. Ma: "A Novel Design Method of LCL Type Utility Interface for Three-Phase Voltage Source Rectifier", in Proc. IEEE PESC'05 Conf., pp.313-317 (2005) 
Leonardo A. Serpa (Non-member) received the B.S. and M.S. de-

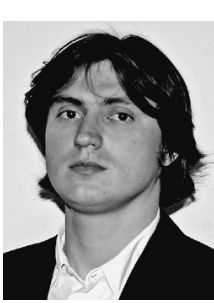
grees in electrical engineering from the Federal University of Santa Catarina, Florianopolis, Brazil in 2002 and 2004, respectively. Between July and December 2001 he worked as an internship student at the Center for Power Electronics Systems in Virginia, USA. He is currently working toward the Ph.D. degree at the Power Electronic Systems Laboratory (PES), Swiss Federal Institute of Technology (ETH), Zurich, Switzerland. His research interests include control strategies of grid-connected inverter systems and multilevel converters. He is currently a member of the Brazilian Power Electronics Society (SOBRAEP).

Johann W. Kolar (Member) received his Ph.D. degree (summa cum

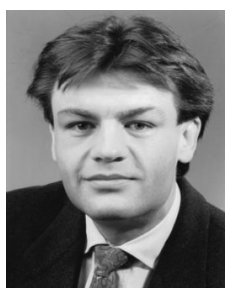
laude) from the University of Technology Vienna, Austria. Since 1984 he has been teaching and working in research, in close collaboration with international industry, in the fields of high performance drives, process technology and uninterruptible power supplies. He has proposed numerous novel converter topologies, e.g., the VIENNA Rectifier and the Three-Phase AC-AC Sparse Matrix Converter concept. Dr. Kolar has published over 250 scientific papers in international journals and conference proceedings and has filed more than 50 patents. He was appointed Professor and Head of the Power Electronic Systems Laboratory at the Swiss Federal Institute of Technology (ETH) Zurich on Feb. 1, 2001. The focus of his current research is on AC-AC and AC-DC converter topologies with low effects on the mains, e.g. for power supply of telecommunication systems, More-Electric-Aircraft and distributed power systems in connection with fuel cells. Further main areas are the realization of ultra-compact intelligent converter modules employing latest power semiconductor technology ( $\mathrm{SiC}$ ), novel concepts for cooling and EMI filtering, multi-domain/multi-scale modelling and simulation, pulsed power, bearingless motors, and Power MEMS. He received the Best Transactions Paper Award of the IEEE Industrial Electronics Society in 2005. He also received an Erskine Fellowship from the University of Canterbury, New Zealand, in 2003. In 2006, the European Power Supplies Manufacturers Association (EPSMA) awarded the Power Electronics Systems Laboratory of ETH Zurich as the leading academic research institution in Europe. Dr. Kolar is a Senior Member of the IEEE and a Member of the IEEJ and of Technical Program Committees of numerous international conferences in the field (e.g. Director of the Power Quality Branch of the International Conference on Power Conversion and Intelligent Motion). From 1997 through 2000 he has been serving as an Associate Editor of the IEEE Transactions on Industrial Electronics and since 2001 as an Associate Editor of the IEEE Transactions on Power Electronics. Since 2002 he also is an Associate Editor of the Journal of Power Electronics of the Korean Institute of Power Electronics and a member of the Editorial Advisory Board of the IEEJ Transactions on Electrical and Electronic Engineering. 